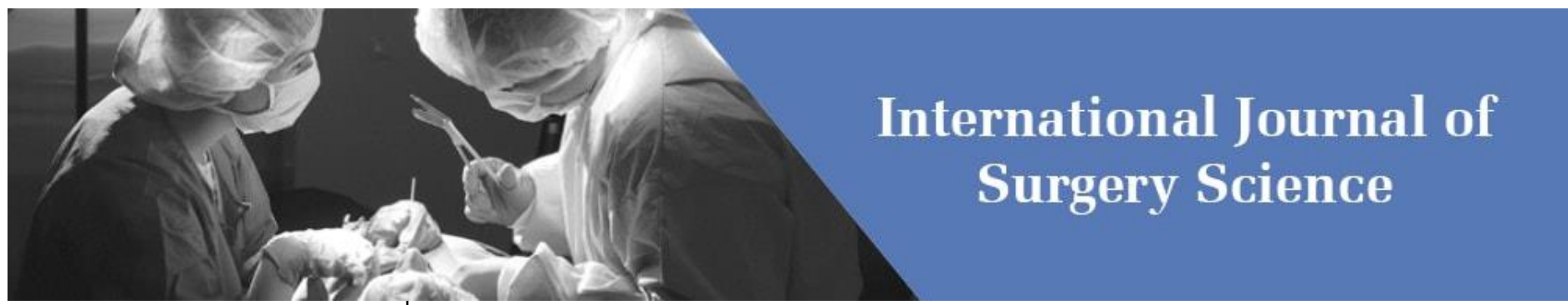

E-ISSN: 2616-3470

P-ISSN: 2616-3462

(C) Surgery Science

www.surgeryscience.com

2019; 3(4): 259-261

Received: 01-08-2019

Accepted: 03-09-2019

\section{Dr. Ranjithkumar}

Third Year Post Graduate,

Department of General Surgery,

Vinayaka Missions Medical College and

Hospital, Karaikal, Vinayaka Missions

Research Foundation (Du), Salem,

Tamil Nadu, India

\section{Dr. B Sankararaman}

M.S, Professor and Unit Chief,

Department of General Surgery,

Vinayaka Missions Medical College and

Hospital, Karaikal, Vinayaka Missions

Research Foundation (Du), Salem,

Tamil Nadu, India

Dr. N Sankar

M.S, Assistant Professor

Department of General Surgery,

Vinayaka Missions Medical College and

Hospital, Karaikal, Vinayaka Missions

Research Foundation (Du), Salem,

Tamil Nadu, India

\section{Dr. T Bharathiraja}

M.S, Senior Resident,

Department of General Surgery,

Vinayaka Missions Medical College and

Hospital, Karaikal, Vinayaka Missions

Research Foundation (Du), Salem,

Tamil Nadu, India

Dr. Jassim A Jabbar

Second Year Post Graduate,

Department of General Surgery,

Vinayaka Missions Medical College and

Hospital, Karaikal, Vinayaka Missions

Research Foundation (Du), Salem,

Tamil Nadu, India

Dr. Shantanu Rao Nilak

First Year Post Graduate,

Department of General Surgery,

Vinayaka Missions Medical College and

Hospital, Karaikal, Vinayaka Missions

Research Foundation (Du), Salem,

Tamil Nadu, India

\section{A case report and review of lumbar hernia}

\author{
Dr. Ranjithkumar, Dr. B Sankararaman, Dr. N Sankar, Dr. T \\ Bharathiraja, Dr. Jassim A Jabbar and Dr. Shantanu Rao Nilak
}

DOI: https://doi.org/10.33545/surgery.2019.v3.i4e.249

\section{Abstract}

The lumbar area is limited by the bone structures (superiorly by the 12th rib and inferiorly by the iliac crest); furthermore, several important nerves including the genitofemoral nerve, lateral femoral cutaneous nerve, ilioinguinal and iliohypogastric nerves are all exposed in this area after retroperitoneal dissection during lumbar hernia repair ${ }^{[1,2]}$, which render the risk and challenge for lumbar hernia repair and mesh fixation. In addition, the superior and inferior lumbar hernias, although had the same name of lumbar hernia, are quite different according to the anatomical location and there is no standard and preferred method for lumbar hernia repair. However, strangulated primary lumbar hernia, although rare, may occur in about $9 \%$ of cases, especially in elderly patients ${ }^{[3,4]}$

Keywords: Lumbar hernia, superior, retroperitoneal

\section{Introduction}

Lumbar hernia is a protrusion of the retroperitoneal, abdominal or intraperitoneal content through a defect in the posterior abdominal wall. It is a rare condition. Approximately $300^{[5]}$ cases noted till now, less than 1-2\% of all abdominal wall hernias, out of which $20 \%$ are congenital and $80 \%$ are acquired. It is more common in the left side than the right side. It is more commonly seen in $5^{\text {th }}$ decade (elderly). Male: female ratio is $2: 1$.

Risk factors include obesity, COPD and weight lifting. There are 2 types of lumbar hernia congenital and acquired. Acquired lumbar hernia includes primary lumbar hernia and secondary lumbar hernia ${ }^{[6]}$. On the basis of anatomy, primary lumbar hernia is divided into Superior lumbar hernia and Inferior lumbar hernia. The superior lumbar triangle is usually larger than the inferior triangle and is a more common site for lumbar hernias. ${ }^{[7]}$ Secondary lumbar hernia can be caused by trauma, previous surgery (commonly urological) and infection. Superior lumbar hernia is the protrusion of abdominal contents through Superior Lumbar Triangle of Grynfeltt-lesshaft (discovered by Grynfeltt in 1866) ${ }^{[8]}$. Boundaries of Superior Lumbar Triangle: Above bounded by $12^{\text {th }}$ rib, Medially by Sacrospinalis, Laterally by Posterior border of Internal Oblique muscle. Inferior lumbar hernia is the Protrusion of abdominal contents through Inferior Lumbar Triangle of Petit (discovered by Petit 1783 ${ }^{[9]}$ whose boundaries are : Below Crest of Ilium, medially Anterior border of Latissimus dorsi, and Laterally Posterior border of External Oblique muscle.

\section{Case}

A 48 year old male patient, working as a farmer came with complaints of swelling in the left loin region since 4 years and backache since 20 days. The patient went for orthopaedic consultation where he was evaluated for low backache where he was suspected to be having lumbar hernia and was referred to surgery department. The swelling initially was small in size, gradually increased and attained the preoperative size. It was associated with dull aching back pain for 20 days, gradual in onset, progressive in nature, radiating to both the legs. No aggravating and relieving factors. History of blunt injury to back 4 years ago, along with history of numbness in both legs and history of weight lifting present. No previous history of any chronic illness, no history of any previous surgery.

On general examination, all the vitals were within normal limits.

On local examination, there was a round to oval swelling present over the Left Lumbar Region measuring $10 \times 6 \mathrm{~cm}$, extending from below the $12^{\text {th }}$ rib to $3 \mathrm{~cm}$ above the iliac crest.
Dr. Ranjithkumar

Third Year Post Graduate,

Department of General Surgery,

Vinayaka Missions Medical College and Hospital, Karaikal, Vinayaka Missions Research Foundation (Du), Salem,

Tamil Nadu, India 
The Surface was Smooth, expansile cough Impulse was present with reduction in size in prone position. It was manually reducible. Consistency was doughy in lower part where as the upper part was soft. On percussion the swelling was resonant in upper portion and had a dull note in lower portion. There was no apparent neurological abnormality found on examination There were no other significant findings clinically.

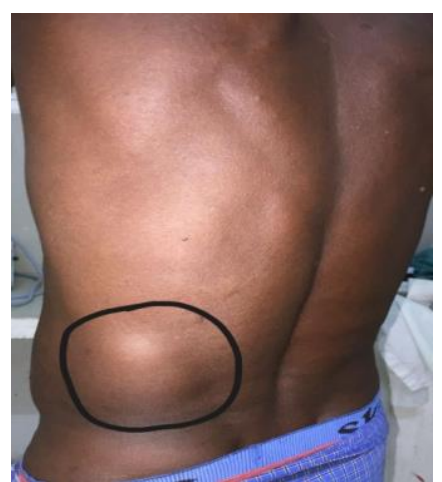

Fig 1: left lumbar hernia

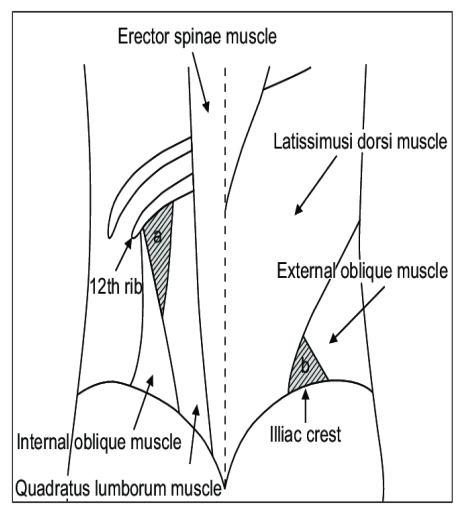

Fig 2: Line diagram of lumbar triangle

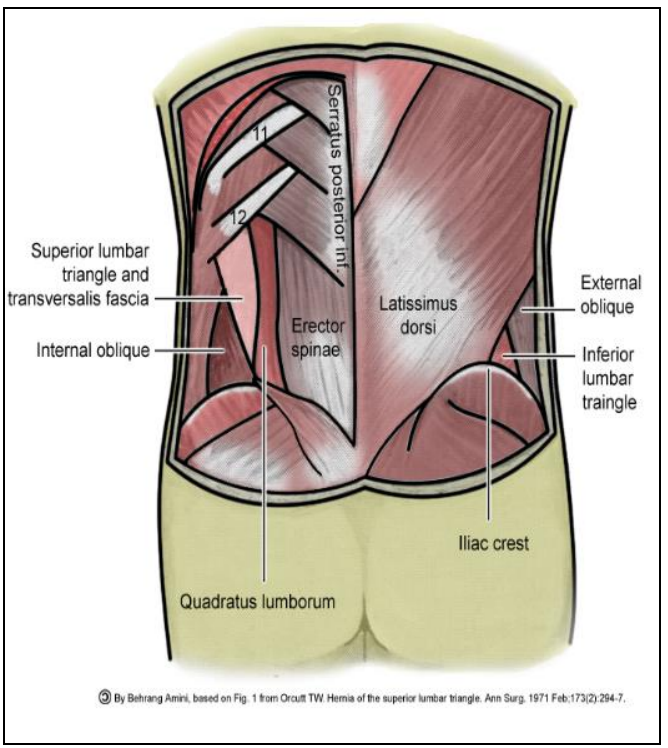

Fig 3: Superior and inferior lumbar triangles

On sonography, Defect was found to be of $2.2 \mathrm{~cm}$, which was confirmed on CT-scan.

The patient required surgical treatment and was posted for open meshplasty.

\section{Anaesthesia}

Spinal anaesthesia

\section{Position of the patient}

Right lateral decubitus position

\section{Operative findings}

Defect identified in both the superior and inferior triangles. The herniating content is retroperitoneal fat, Both the triangles are communicating underneath the lumbar fascia

\section{Procedure}

After the spinal anaesthesia the patient was put in right lateral decubitus position. Oblique skin incision in the region of the hernia was made. Defect identified in both the superior and inferior triangles. The herniating content is retroperitoneal fat, both the triangles are communicating underneath the lumbar fascia, the contents were reduced to retroperitoneal space. Defect is closed with non absorbable Polypropylene mesh repair. Inlay- Onlay method was used.

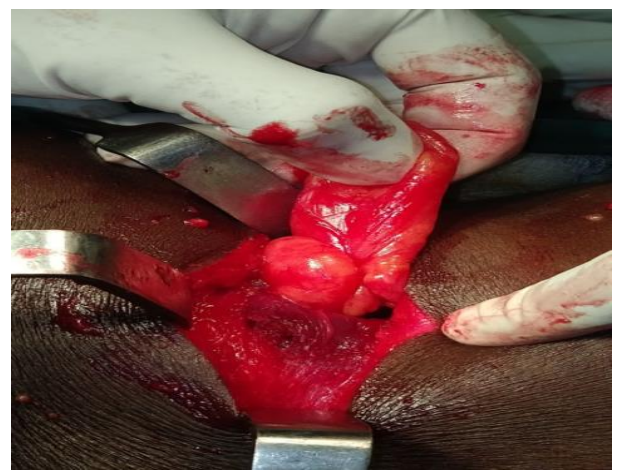

Fig 4: Herniation of retro-peritoneal fat through the defect

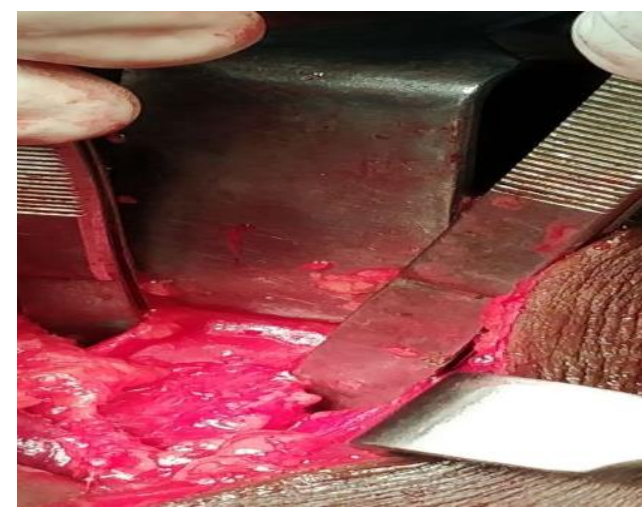

Fig 5: Superior lumbar defect

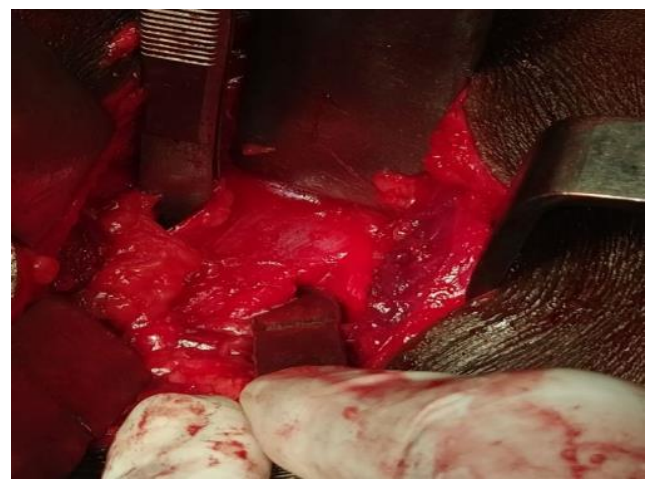

Fig 6: Inferior lumbar defect 


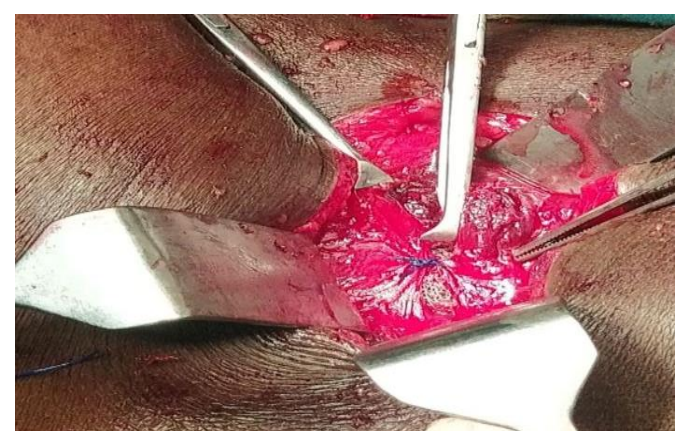

Fig 7: Inlay mesh fixing

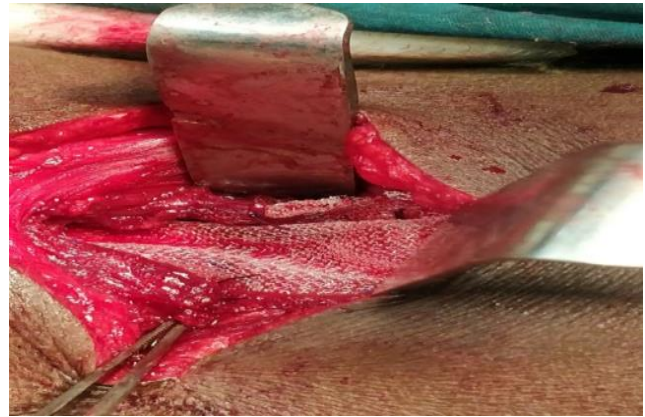

Fig 8: Onlay mesh fixing

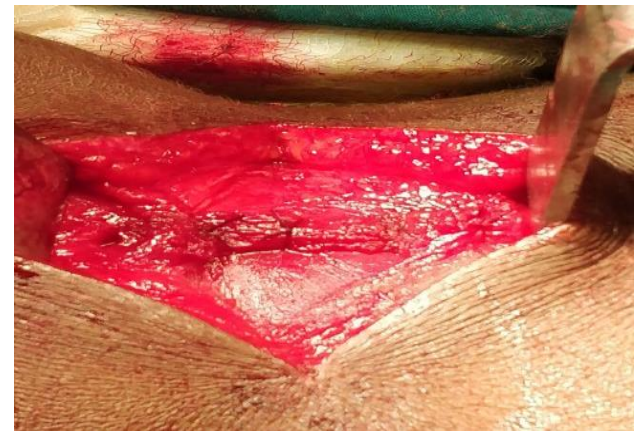

Fig 9: closure of latisimus dorsi

\section{Discussion}

Primary lumbar hernias present most commonly as a palpable mass which increases in size on coughing. They are usually reducible and may disappear in supine position. Patient may present with nonspecific abdominal pain or back pain which may represent sciatica. There are occasions when lumbar hernias may lead to ureteric obstruction resulting in hydronephrosis. The most common differential diagnoses are lipomas, fibromas, haematomas, abscesses, intra abdominal /retroperitoneal tumours and panniculitis. X-ray may not be helpful, but CT scan remains to be gold standard for diagnosis. In selected patients, MRI also has a role in diagnosis and planning in the surgical treatment. Surgical treatment is the only option and it should be considered early to avoid complications.

\section{Conclusion}

Lumbar hernias are rare. A good clinical history and general physical examination can rule out most of the differential diagnoses. A CT scan should be done as a routine prior to planning surgical approach. Open surgeries should be reserved for patients with large and multiple defects as it was in our case.

\section{Reference}

1. Moreno- Egea A, Alcaraz AC, Cuervo MC. Surgical options in lumbar hernia: Laparoscopic versus open repair.
A long- term prospective study. Surg Innov. 2013; 20:33144

2. Moreno- Egea A, Alcaraz AC, Cuervo MC. Surgical options in lumbar hernia: Laparoscopic versus open repair. A long- term prospective study. Surg Innov. 2013; 20:33144

3. Fokou M, Fotso P, Ngowe Ngowe M, Essomba A, Sosso M.Strangulated or incarcerated spontaneous lumbar hernia as exceptional cause of intestinal obstruction: Case report and review of the literature. World J Emerg Surg. 2014; 9:44.

4. Ka I, Gueye ML, Thiam O, Akpo LG, Toure AO. Strangulatedlumber hernias in adults: A case report and review of the literature. Ann R Coll Surg Engl. 2016; 98:160-1.

5. Moreno- Egea A, Baena EG, Calle MC, Martínez JA, Albasini JL.Controversies in the current management of lumbar hernias. Arch Surg. 2007; 142:82-8.

6. Bittner R, Bingener- Casey J, Dietz U, Fabian M, Ferzli G, Fortelny R, et al. Guidelines for laparoscopic treatment of ventral and incisional abdominal wall hernias (International Endohernia Society [IEHS])- part III. Surg Endosc. 2014; 28:380-404

7. Cavallaro G, Sadighi A, Paparelli C. Anatomical and surgical considerations on lumbar hernias. Arch Surg. 2007; 142:82-8.

8. Grynfeltt J. Quelque mots sur la hernie lombaire. Montp Med. 1866; 16:329.

9. Petit L. Trait des maladies chirurgicales. Vol. 2. Paris: Masson, 1783. 